\title{
EDUCAÇÃO HUMANIZADORA E O PODER DA LITERATURA EM TEMPOS DE \\ PANDEMIA DO COVID-19
}

\author{
HUMANIZING EDUCATION AND THE POWER OF LITERATURE IN COVID-19 PANDEMIC \\ TIMES
}

\section{HUMANIZACIÓN DE LA EDUCACIÓN Y EL PODER DE LA LITERATURA EN TIEMPOS DE \\ PANDEMIA COVID-19}

\author{
Alcione Salete Alba Dall Pilger ${ }^{1}$ \\ Ana Paula Teixeira Porto²
}

\begin{abstract}
RESUMO
A construção de um processo educacional humanizador é o tema central deste artigo que, especificamente, discute o papel da literatura como instrumentos essencial de formação humana e cidadã. A partir de teses de Antonio Candido, a pesquisa de teor bibliográfico mostra como a literatura pode ser uma ferramenta de leitura importante na formação do sujeito e em contextos de dificuldades educacionais, como o enfrentado no contexto da pandemia da COVID-19.
\end{abstract}

Palavras-chave: Educação humanizadora. Literatura. Pandemia COVID-19.

\section{ABSTRACT}

The construction of a humanizing educational process is the central theme of this article, which specifically discusses the role of literature as an essential instrument of human and citizen formation. Based on theses by Antonio Candido, the bibliographic research shows how literature can be an important reading tool in the formation of the subject and in contexts of educational difficulties, such as that faced in the context of the COVID-19 pandemic.

Keywords: Humanizing education. Literature. COVID-19 pandemic.

\section{RESUMEN}

La construcción de un proceso educativo humanizador es el tema central de este artículo, que aborda específicamente el papel de la literatura como instrumento esencial de la formación humana y ciudadana. A partir de las tesis de Antonio Candido, la investigación bibliográfica muestra cómo la literatura puede ser una importante herramienta de lectura en la formación del sujeto y en contextos de dificultades educativas, como el que se enfrenta en el contexto de la pandemia COVID-19.

Palabras clave: Humanización de la educación. Literatura. Pandemia de COVID-19.

1 Graduada e Mestre em Letras. E-mail: alcionesaletedalalba@hotmail.com

2 Graduada, Mestre e Doutora em Letras e professora do Programa de Pós-graduação - Mestrado e Doutorado em Educação da URI-FW. E-mail: anapaulateixeiraporto@gmail.com 


\section{INTRODUÇÃO}

Em distintas obras, como Pedagogia da Autonomia (2001) e Pedagogia do Oprimido (2005), Paulo Freire já acentuava o papel fundamental que uma educação humanizada e libertadora pode exercer na formação cidadã, de modo a fomentar um processo educativo baseado na construção de uma sociedade mais justa e igualitária, em que todas as vozes tenham sua representatividade e sejam ouvidas e respeitadas. Suas lições não são recentes, no entanto fundamentais para compreendermos 0 tempo contemporâneo, mais precisamente 0 que se atravessa a partir de 2020 - uma época que exige de educadores distintas reinvenções em seu campo de atuação profissional.

É sobre este novo tempo que pretendemos apresentar uma discussão, fundamentada em pesquisas bibliográficas, a partir de um enfoque direcionado à educação, especificamente ao papel humanizador que ela precisa ainda mais desempenhar em momentos complexos, tendo como elemento significativo a literatura. Esta é compreendida como um instrumento legítimo de potencializar a formação humana e, portanto, um direito de todos, conforme defende Antonio Candido (1995). Dessa forma, pretendemos assinalar a importância da leitura literária como prática necessária para enfrentamento das dificuldades educacionais decorrentes da pandemia de Covid19, especialmente por sua potencialidade enquanto objeto de uma formação humanizadora.

Ao experienciarmos a pandemia da Covid-19 (coronavirus disease-19), precisamos pontuar que o novo momento histórico ocasiona não apenas inúmeras alterações nos sistemas de saúde, no convivio social, nos hábitos sociais, nos processos de gestão, na economia, mas também na educação, que precisou, de forma emergencial, adaptar-se a novas realidades. Com a substituição dos momentos presenciais pelos remotos, realizados com ou sem uso de tecnologias digitais para atividades assíncronas, a palavra-chave do contexto é reinvenção pedagógica, pois esses tempos trouxeram

uma ressignificação para a educação, nunca antes imaginada. A dor causada pela perda de pessoas, o afastamento, o isolamento social, causaram uma desestruturação no sistema regular e presencial de ensino. A crise sanitária está trazendo uma revolução pedagógica para o ensino presencial, a mais forte desde 0 surgimento da tecnologia contemporânea de informação e de comunicação. (PASINI; CARVALHO; ALMEIDA; 2020, p.3)

A partir dos primeiros meses de 2020, que se apresenta como um marco na sociabilidade contemporânea pela configuração de uma pandemia, exigindo, no campo educacional, a revisão de conceitos, práticas e metodologias de ensino e de aprendizagem, assim com de avaliação, a 
relevância dos ensinamentos freireanos e a importância de uma educação mais humanizadora tornam-se mais evidentes. Dessa forma, em tempos de isolamento social, de incertezas quanto ao futuro dada a existência de um novo vírus em constante mutação que tem exterminado milhares de vidas, 0 acolhimento e a empatia tornam-se valores essenciais para superação das diversas dificuldades que o contexto pandêmico impõe.

Com o distanciamento físico entre os sujeitos experienciado também no campo educacional, como possibilitar uma educação humanizadora sem o contato presencial entre professores e alunos? No que investir para o fortalecimento da sensibilização e da empatia nas relações humanas? Que instrumentos, que não necessitam do contato pessoal entre sujeitos para projeção de seus efeitos profícuos, podem ser mais explorados, sendo acessível a professores e alunos? Que objetos, acessíveis a uma prática educadora, podem ser melhor explorados?

Partindo desses questionamentos, propomos a tese de que, na realidade pandêmica vivenciada por educadores, gestores e alunos, o trabalho com a leitura literária ganha novos significados e importância numa perspectiva educacional humanizadora. Ao contemplarmos essa discussão, partimos inicialmente de uma abordagem sobre a importância da literatura, sua potencialidade enquanto instrumento de formação humana; em seguida apresentamos alguns exemplos de textos literários que se revelam excelentes instrumentos para práticas de educação humanizadora através da leitura literária, especialmente para um contexto de pandemia.

\section{A LITERATURA E SEU POTENCIAL HUMANIZADOR}

Todorov, no livro A literatura em perigo (2009), discorre que a literatura está em perigo pelo fato de os verdadeiros leitores estarem cada vez mais escassos. Está em perigo também por não ver a literatura sendo tratada como forma de conhecimento sobre o homem, mas como pretexto de teorias, análises, aponta o pesquisador. No penúltimo capítulo do livro, o crítico questiona acerca de "O que pode a literatura", apresentando nele a interface curativa e libertadora do homem:

[...] a literatura pode muito. Ela pode nos estender a mão quando estamos deprimidos, nos tornar ainda mais próximos dos outros seres humanos que nos cercam, nos fazer compreender melhor o mundo e nos ajudar a viver. Não que ela seja, antes de tudo, uma técnica de cuidados para com a alma; porém, revelação do mundo, ela pode também, em seu percurso, nos transformar a cada um de nós a partir de dentro. (TODOROV, 2009, p. 76) 
Essa transformação proporcionada pela literatura ao homem é subjetiva - pode ocorrer dentro de cada um, de maneira diversa em cada indivíduo. Na perspectiva de Todorov (2009), a literatura ajuda a viver, permite a cada um responder melhor à vocação de ser humano, amplia nosso universo ao abrir infinitas possibilidades de interação. É nessa perspectiva que o autor pontua que:

\begin{abstract}
Mais densa e mais eloquente que a vida cotidiana, mas não radicalmente diferente, a literatura amplia o nosso universo, incita-nos a imaginar outras maneiras de concebê-lo e organizá-lo. Somos todos feitos do que os outros seres humanos nos dão: primeiro nossos pais, depois aqueles que nos cercam; a literatura abre ao infinito essa possibilidade de interação com os outros e, por isso, nos enriquece infinitamente. Ela nos proporciona sensações insubstituíveis que fazem o mundo real se tornar mais pleno de sentido e mais belo. Longe de ser um simples entretenimento, uma distração reservada às pessoas educadas, ela permite que cada um responda melhor à sua vocação de ser humano. (TODOROV, 2009, p. 23 e 24)
\end{abstract}

Se, por um lado, reconhecemos o valor da literatura como forma de vivermos melhor, também podemos nos tornar mais humanos pelas possibilidades de interação com os outros que ela nos proporciona, conforme proposta já defendida por Antonio Candido (1995) em "O direito à literatura" ao defender a literatura como um bem e um dos direitos fundamentais do ser humano, desenvolve em cada um a compreensão de si e de seu semelhante. Assim sendo, a principal função da literatura está relacionada à humanização do homem que "confirma o homem na sua humanidade", fazendo-nos exercer aquilo que faz de nós seres humanos: a reflexão, relação com o outro, o sentido da beleza, a sensibilidade, a complexidade do mundo e das coisas. 0 autor explica-nos através da definição de humanização, o que confirma traços essenciais do homem:

Entendo aqui por humanização (já que tenho falado tanto nela) o processo que confirma no homem aqueles traços que reputamos essenciais, como o exercício da reflexão, a aquisição do saber, a boa disposição para com o próximo, o afinamento das emoções, a capacidade de penetrar nos problemas da vida, o senso da beleza, a percepção da complexidade do mundo e dos seres, o cultivo do humor. A literatura desenvolve em nós a quota de humanidade na medida em que nos torna mais compreensivos e abertos para a natureza, a sociedade, o semelhante. (CANDIDO, 1995, p. 249)

Dessa forma, na definição de humanização são mencionados traços essenciais do homem que permitem refletir que a literatura exerce uma função social importante, pois contribui para a formação integral do homem, humanizando-o na medida que o torna mais compreensivo com o semelhante e com a sociedade que está inserido. Assim, a literatura, na visão de Candido, 
"desenvolve em nós a quota de humanidade na medida em que nos torna mais compreensivos e abertos para [...] a sociedade, o semelhante" (CANDIDO, 1995, p.249).

Nesse contexto, quanto mais igualitária for a sociedade haverá maior humanização, maior difusão das obras literárias que contribuem para o amadurecimento de cada um. Assim, 0 direito aos direitos humanos não pode ser negado, Candido (1995, p. 263) destaca: "Uma sociedade justa pressupõe o respeito dos direitos humanos, e a fruição da arte e da literatura em todas as modalidades e em todos os níveis é um direito inalienável". Do contrário: "Negar a fruição da literatura é mutilar a nossa humanidade". (CANDIDO, 1995. p. 256). Portanto, na luta pelos direitos humanos, todos devem ter condições de acesso à fruição da literatura, já que ela é um fator indispensável de humanização e constitui-se como uma necessidade de equilíbrio do homem e da sociedade.

A importância da literatura reside no equilíbrio humano, pois segundo o crítico, o texto literário atua em grande parte no inconsciente e no subconsciente. Daí a literatura tornar-se uma necessidade universal e um fator indispensável de humanização:

\footnotetext{
Portanto, assim como não é possível haver equilíbrio psíquico sem o sonho durante 0 sono, talvez não haja equilíbrio social sem a literatura. Deste modo, ela é fator indispensável de humanização e, sendo assim, confirma o homem na sua humanidade, inclusive porque atua em grande parte no subconsciente e no inconsciente. Neste sentido, ela pode ter importância equivalente à das formas conscientes de inculcamento intencional, como a educação familiar, grupal ou escolar. (CANDIDO, 1995, p. 243)
}

Nessa reflexão, podemos explicitar a importância da literatura como meio de instrução e educação do ser humano, para que vivencie plenamente sua humanidade com equilíbrio.

Por conseguinte, reconhecemos a importância da literatura para a formação do homem. De acordo com reflexão proposta por Candido $(1972,1995)$ já é consensual que a literatura é um instrumento de humanização, de formação do homem, sendo um direito, cabe-nos criar condições a fim de que esse direito seja respeitado. 0 crítico ao defender a ideia de que a literatura é um dos direitos fundamentais do homem, justamente porque ela, que exprime o homem, depois atua sobre ele, organiza a experiência e é uma força de humanização, da qual todos deveriam ter acesso; ninguém deveria ser privado.

Em perspectiva similar ,Antonio Candido, no texto "A literatura e a formação do homem”, menciona a literatura "como força humanizadora, não como sistema de obras. Como algo que exprime o homem e depois atua na própria formação do homem". (CANDIDO,1972, p. 82). Faz 
isso ao pensar no papel da literatura apresenta as seguintes funções: psicológica, formativa e social.

Função psicológica está embasada na capacidade que a literatura tem de atender à nossa imensa necessidade da ficção e da fantasia, da fruição de agradar aos nossos sentidos, devaneio, prazer da leitura. Segundo o crítico, a fantasia está relacionada à determinada realidade:

\begin{abstract}
Serve para ilustrar em profundidade a função integradora e transformadora da criação literária com relação aos seus pontos de referência da realidade. Ao mesmo tempo, a evocação dessa impregnação profunda mostra como as criações ficcionais e poéticas podem atuar de modo subconsciente e inconsciente, operando uma espécie de inculcamento que não percebemos. (CANDIDO, 1972, p.84).
\end{abstract}

A função formativa faz um elo com a formação humana que nos forma, que atua sobre nós, representa um caráter formativo, segundo o autor: "Ela não corrompenem edifica, portanto; mas, trazendo livremente em si o que chamamos o bem e o que chamamos o mal, humaniza em sentido profundo, porque faz viver". (CANDIDO, 1972, p. 85).

Por último, a função da literatura como representação da realidade social e humana leva em conta a estética e o arranjo do texto, pois a constituição de seu sentido atrela-se a dois elementos-chave: o tema e a forma. Essa função tem o potencial de oferecer ao leitor um conhecimento através da obra literária, tal qual faz a ciência, mas por outro caminho:

... a obra literária significa um tipo de elaboração das sugestões da personalidade e do mundo que possui autonomia de significado, mas que essa autonomia não a desliga das suas fontes de inspiração no real, nem anula a sua capacidade de atuar sobre ele. (CANDIDO, 1972, p. 86)

Nesse sentido, reside a potencialidade formativa que um texto literário pode contemplar, em um movimento que, diferentemente de textos de viés injuntivo, doutrinador, investe na sugestividade da reflexão por meio da linguagem literária, seus arranjos e sua entonação temática. Em observação à tese de Candido (1972) sobre a capacidade humanizadora que a literatura, Pereira e Cavalcanti $(2019$, p. 68) acentuam:

Antonio Candido já apontava três aspectos da obra literária importantes em seu processo humanizador. Além da capacidade que a literatura tem de atender à nossa necessidade de fabulação, o crítico ressalta sua natureza essencialmente formativa, que se opõe, no entanto, ao caráter pedagógico e doutrinador de outros textos. 
Além disso, a obra literária é uma forma de expressão e construção artística, e uma forma de conhecimento. Isto posto, podemos observar essa função da literatura como representação da realidade social e humana com possível caráter verossímil. É importante salientar que essa compreensão e identificação do valor da literatura pode ser cultivada e desenvolvida através da leitura como prática cotidiana, pois, segundo Letícia Malard (1985, p.11), "o melhor caminho para se aprender a literatura é a leitura". Então, que seja estimulada a leitura de literatura não apenas como meio de entretenimento, mas também de reflexão sobre a condição e existência humana.

Para Zilberman (1999), a literatura exerce uma função social importante. É através dela que

O indivíduo abandona temporariamente sua própria disposição e preocupa-se com algo que até então não experimentara. Traz para o primeiro plano algo diferente dele, momento em que a vivência - a alteridade como se fosse ele mesmo. (ZILBERMAN, 1999, p.84)

Uma das funções da literatura é ser verossímil, não verdadeira, o que permite aos leitores reconhecer cenas e situações ficcionais e, com isso, melhor compreender a realidade que o cerca dadas as filiações entre o real e o imaginário construídas pelo texto literária. Constitui-se a literatura, dessa forma, uma forma de apropriação do mundo pela linguagem - outro elemento que instiga a percepção, a análise, a observação do leitor. A linguagem literária, o traço distintivo da literatura em relação a outros textos, é elemento singular por, conforme Aguiar e Silva (1976. p. 51),

A linguagem literária é plurissignificativa porque nela as frases, as palavras, as sequências são portadoras de múltiplas dimensões semânticas, tendendo para uma multivalência significativa, diferente do discurso científico.

O leitor penetra na linguagem conotativa que trata de beleza e encanto. Cabe a ele tirar as conclusões da conclusão e das sugestões conclusivas do texto que lê. Assim, a obra será um veículo do conhecimento que vai além do real. Essa forma de conhecimento via ficção, que tem como meio a linguagem artisticamente elaborada e que possibilita uma visão do homem, da natureza e do mundo.

Nessa mesma linha de raciocínio Maria da Gloria Bordini e Vera Aguiar (1993) enfatizam que a literatura tem o poder de oferecer ao leitor um mundo diferente do que ele vivencia, o que 
também permite um distanciamento entre a realidade vivida e uma outra que passa a ser experienciada pela leitura. Nas palavras das autoras:

[...] a riqueza polissêmica da literatura é um campo de plena liberdade para o leitor, 0 que não ocorre em outros textos. Daí provém o próprio prazer da leitura, uma vez que ela mobiliza mais intensa e inteiramente a consciência do leitor, sem obrigá-lo a manter-se nas amarradas do cotidiano. Paradoxalmente, por apresentar um mundo esquemático e pouco determinado, a obra literária acaba por fornecer ao leitor um universo muito mais carregado de informações, porque o leva a participar ativamente da construção dessas, com isso forçando-o a reexaminar sua própria visão da realidade. (BORDINI; AGUIAR, 1993, p.15).

Observamos que a literatura permite que o leitor pela polissemiado texto literário construa múltiplas significações na medida em que utiliza a leitura de mundo internalizada. Segundo Bordini e Aguiar (1993): "[...] a atividade do leitor de literatura se exprime pela reconstrução, a partir da linguagem, de todo o universo simbólico que as palavras encerram e pela concretização desse universo com base nas vivências pessoais do sujeito". (BORDINI; AGUIAR, 1993, p15).

Ainda possibilita ao leitor refletir e reexaminar a visão que tem da realidade, bem como fazer experiências por um mundo paralelo ao seu:"A literatura, desse modo, se torna uma reserva de vida paralela onde o leitor encontra o que não pode ou não sabe experimentar na realidade".(BORDINI; AGUIAR, 1993, p. 15). A apropriação dos textos pelo leitor desenvolve a consciência de que a possibilidade de leitura se efetiva por um processo de aprendizado particular. Este aprendizado depende dos modos de ler, do conhecimento que possui, dos sentidos que descobre nos textos.

Podemos compreender a literatura como arte e retomar Candido (1995), é direito de todo homem 0 acesso à arte, sendo ela um dos responsáveis por consolidar o universo de conhecimento, assim como os demais direitos básicos do ser humano, indiferentemente de classe social. Assim, ela possui uma importância para a sociedade e o homem que nela vive. Uma das marcas do exercício da arte e da literatura é a busca da liberdade do homem de todas as amarras que a sociedade lhe impõe. Nesse sentido, que ela é transfiguradora, transgressiva e revolucionária.

A literatura é uma linguagem artística, enquanto arte envolve um fazer, revela uma consciência muito clara por parte do artista, através de seu material que é a palavra. $O$ trabalho do artista da palavra tem algo muito importante a dizer, e este algo é diferente dos outros, pois irá lidar com a sensibilidade das pessoas, com a universalidade do pensamento, com o estilo, o que 
gera o refinamento do nosso espírito. Enfim, envolve uma complexidade de comportamentos, pois utiliza a palavra como instrumento essencial na busca do belo. Como produto da atividade humana possibilita refletir sobre questões próprias da condição humana: vida, morte, tristeza, alegria, amor, o que as demais artes, só o conseguem num determinado momento ou circunstância.

Na perspectiva de Aguiar e Silva (1976, p. 111):

[...] toda obra literária autêntica traduz uma experiência humana e diz algo acerca do homem e do mundo... a literatura exprime sempre determinados valores, dá forma a uma cosmovisão, revela almas - em suma, constitui um conhecimento.

Dessa forma, a literatura é fruto de uma experiência, está intimamente ligada à realidade, revela-se de uma forma figurada e atinge o mais íntimo do homem, mostra o contexto social, ou a vivência de uma época. A literatura sempre foi um documento histórico. Assume uma importância maior do que somente uma diversão.

A literatura serve para lidar com manifestações criativas, como espaço para 0 desenvolvimento da sensibilidade, permitir 0 afloramento das emoções. 0 seu consumo induz a práticas socializantes. Trata-se de uma convivência democrática ao respeitar o outro, conviver com a diversidade e ser capaz de assumir outros ângulos de visão. Esse exercício que o leitor faz ao vivenciar emoções alheias, diferentes, ao entrar na pele dos personagens, é um exercício de cidadania. Dado o exposto, a literatura é importante para a formação cidadã. Para finalizar essa reflexão, podemos dizer que por dar voz ao leitor a literatura se torna um importante instrumento de emancipação do sujeito.

No artigo "O sentido formativo da literatura", Adélia Bezerra de Meneses([s. d], p. 7) questiona: "qual o papel da Literatura e por que ensinar Literatura?: Tenta uma resposta parcial numa síntese difícil: "a Literatura, esse exercício radical da Palavra, contrapõe o Logos (que é Palavra e que é Razão) ao mundo anestesiante da imagem". Assim, a literatura é constituidora da palavra e a palavra é constituidora do humano.

Numa era de crise das humanidades, da universidade "que não fica imune aos valores correntes", no seio de uma sociedade tecnológica, num mundo massificado, globalizado, no qual se prioriza a mídia e a cultura do espetáculo, cabe-nos refletir sobre qual o papel da literatura e por que ensinar literatura? Nas palavras da autora investir em literatura "é essa a nossa trincheira da resistência" 
Ainda, o fundamental mote da fala da autora é: "Por que literatura?", "Por que ler Homero, Dante, Machado de Assis, Camões, Proust, Drummond, Adélia Prado? Por que investir tempo lendo poesia?" Meneses, ([s. d], p. 9) revela:

\begin{abstract}
Efetivamente a literatura não é passatempo nem verniz de cultura geral. É um veículo de experiência humana, ela forja a sensibilidade, é um instrumento poderoso de humanização, de conhecimento, de si, do outro, do mundo. A literatura é uma leitura do social e é uma leitura do humano, seja no cotidiano da vida pessoal, seja na "epicidade" do destino histórico.
\end{abstract}

Nesse sentido, podemos pensar na função "formativa" da literatura abordada pela autora como "veículo de experiência humana", "instrumento poderoso de humanização, de conhecimento, de si, do outro, do mundo" e relacioná-la à ideia de Antonio Candido (2004) ao defender que a literatura é força humanizadora, dá forma aos sentimentos e à visão do mundo, liberta o homem e o humaniza. Assim, podemos afirmar a importância da literatura para a formação humana.

Além disso, para Todorov (2009) o texto literário para fazer as conexões com o mundo real e com a vida contemporânea precisa ocupar o centro na formação de alunos e professores de literatura, na nossa formação cidadã e nos cursos de literatura, não a periferia do processo educacional. Nessa mesma visão, Letícia Malard (1985) defende que o ponto de partida para 0 ensino de literatura é o texto, refutando o ensino a partir da periodização. Para a autora a literatura:

[...]é uma prática social tanto para quem a escreve quanto para quem a lê. Prática social no sentido de atividade humana em intenção transformadora do mundo, que expressa 0 peculiar da relação do homem com o mundo, os modos de ser do homem no mundo" (MALARD, 1985, p. 10).

Nesse entendimento, a leitura dos textos literários e a crítica sobre eles, ainda é o melhor caminho para a aprendizagem da literatura. $O$ texto literário ao possibilitar a humanização do leitor e potencializar sua leitura crítica e reflexiva da sociedade que faz parte, transforma o leitor e a sociedade. Essa é a prática social da literatura da qual se refere Malard (1985). Portanto, no processo educacional, a leitura do texto literário proporciona ao leitor reconhecer-se, humanizarse.

Referente à formação que a literatura proporciona através de seu ensino, Ourique $(2015$, p. 200) argumenta:

a significação do ensino de Literatura parece ser muito mais relevante se este for capaz de oportunizar condições à formação das pessoas para sua individualidade e, ao mesmo tempo, para sua atuação na sociedade em que vive. 0 ensino, dessa forma, não pode 
estar dissociado da formação e nem a noção de formação se afastar da sociedade e das problemáticas culturais.

Nesse sentido, o ensino de literatura torna-se relevante na medida em que oportuniza a formação do indivíduo para que como sujeito possa atuar no meio em que vive. Para que a literatura cumpra sua função, o ensino deve estar atrelado à formação e esta não poderá estar dissociada da sociedade e da cultura. Ourique $(2015$, p. 13) "acredita ser a principal função da literatura oferecer condições para a formação cultural das pessoas e não essa prática comum de formar um leitor para algo". Assim, para o autor a literatura tem a função de formar pessoas e sua apropriação não deve estar relacionada a nenhuma função com viés utilitário.

Compartilhamos com Porto e Porto $(2015$, p. 90$)$ a ideia de que a literatura possibilita a ampliação formativa de sujeitos e a compreensão do mundo do qual fazem parte. A prática da leitura e o contato com textos literários proporcionam uma emancipação pessoal e condições de intervenção social. Assim as autoras se posicionam:

\footnotetext{
Nesse contexto de formação cultural, entendemos que o desenvolvimento da habilidade de leitura é fundamental para a ampliação de horizontes formativos de sujeitos e para a compreensão do mundo de que fazem parte, o que pode acarretar uma emancipação pessoal e condições de intervenção social e ampliação de defesa de si. Além disso, a prática de leitura de textos e o contato intenso com textos literários possibilitam a revelação sobre si mesmo.
}

Nesse sentido, podemos sintetizar que a literatura apresenta potencialidades formativas, como meio de formação cultural e leitora; formadora de sujeitos críticos, conhecedores da realidade circundante; capazes de alicerçar a conduta ética no trato social, com o intuito de aperfeiçoarmos as inter-relações humanas; capazes de desenvolver em cada um a compreensão sobre si mesmo e seu semelhante, bem como a sensibilidade e a inteligência para habilitarmo-nos a realizar uma leitura mais abrangente do mundo. Dentre outras potencialidades formativas reconhecidas da literatura, podemos ressaltar que pelo fato de dar voz ao leitor, possibilita a emancipação do sujeito, também pode ser vista como meio de instrução e educação importante para o equilíbrio humano e social. Por conseguinte, reconhecemos o valor da literatura como arte, construtora da experiência humana, como um bem e um direito para a formação do homem.

A LITERATURA PARA FORMAÇÃO HUMANIZADORA: ALGUMAS SUGESTÕES DE LEITURA 
Nesta seção, destacamos alguns exemplos de contos, textos mais curtos que permitem uma leitura fluida e rápida e com vários elementos que prendem atenção dos leitores, instigandoos à leitura integral dos textos. Indicamos também narrativas curtas de autores de diferentes contextos como forma também de ampliar o rol de leituras literárias em uma perspectiva mais ampla, para além da literatura nacional e canônica. Todas as sugestões, em nossa perspectiva, são ótimos objetivos para sinalizar a potencialidade da literatura enquanto instrumento de uma prática educativa humanizadora.

Também esclarecemos que selecionamos referências de obras que trazem, tanto na forma quanto na abordagem temática, uma proposição que permite a reflexão do leitor no sentido de compreender a condição humana em contextos complexos. Elas permitem compreender o outro a partir de situações fictícias que se assemelham a experiências de muitas realidades, atenuando distanciamentos, mas também permitindo transitar por uma outra experiência de reflexão através da leitura. Entendemos que as leituras de obras com esse perfil são importantes para aguçar a sensibilidade do leitor e permitir uma maior humanização em práticas educativas em que esses textos sejam objetos de leitura.

Iniciamos as sugestões com a indicação de dois contos de dois autores africanos que escrevem em língua portuguesa. São os contos "Nós Matamos Cão Tinhoso", publicado em 1964 e escrito pelo moçambicano Luís Bernardo Honwana e "Nós chorámos pelo Cão Tinhoso", de 2007 de autoria do angolano Ondjaki. Em ambas as narrativas, segundo Khalil (2012), os personagens devem obedecer às ordens impostas pelas pessoas de maior poder aquisitivo, caso contrário sofrem punições, o que permite ao leitor reconhecer as relações sociais e de trabalho entre 0 branco colonizador e o africano colonizado. Nesse sentido, os enredos das duas histórias, que estabelecem um diálogo intertextual muito interessante, são oportunidades de reconhecer relações entre história africana e ficção a partir de uma linguagem sensivel dos dois contos.

Em "Nós Matámos o Cão Tinhoso", de Luís Bernardo Honwana, o enredo gira em torno de um narrador-personagem chamado Ginho, que faz parte de um grupo de meninos que foram escolhidos para matar um cão abandonado, doente que está prestes a morrer. O Cão é denominado Cão Tinhoso, e através do narrador, que hora representa ter afeto, hora representa ter indiferença pelo cão, é possível saber tudo sobre o animal. A morte desse cão foi encomendada por um veterinário da cidade, segundo ele esse animal estava em condições muito precárias para viver entre a sociedade. De acordo com Khalil (s.d) esse animal representa aquilo que ninguém quer ver "o feio, o doloroso, o asqueroso, o que fede" (KHALIL, s.d, p. 196). 
A narrativa "Nós Chorámos pelo Cão Tinhoso", de Ondjaki, consiste em uma aula de português na qual os alunos precisam ler o conto de Hanwana, porém o narrador, que também é um menino, lembra que anteriormente já havia lido esse determinado conto e fica apreensivo por ter que ler essa história novamente. A professora seleciona alguns alunos para fazer a leitura, se fosse em um dia comum isso seria ótimo, pois ela só escolhe quem lê bem, mas naquele dia 0 prêmio se tornou castigo, ninguém queria ser escolhido pelo forte enredo retratado naquela narrativa. A regra imposta na sala de aula é a de que quem chorar seria considerado "marica", então todos se afligiam por não poder demonstrar tamanha emoção, somente segurar para si aquela angústia de não poder ajudar o Cão Tinhoso.

A leitura desses dois textos parece-nos pertinente não apenas por possibilitar o trânsito para contexto da literatura africana de língua portuguesa, alargando os limites de estudo da literatura nacional, mas também por suscitar experiências de emoção, empatia que as narrativas ensejam. Além disso, a linguagem, mesmo que não seja a do português brasileiro, é acessível e muito bem articulada, chamando o leitor para cada parágrafo das narrativas.

No contexto da literatura brasileira recente, salientamos a antologia de contos Gosto de Amora, de Mário Medeiros. Publicada em 2019, a obra é um livro sobre a vida que relata histórias protagonizadas e narradas por homens negros - algo muito importante de observar considerado uma realidade brasileira que inviabiliza e menospreza experiências de sujeito marginalizados histórica, social e sexualmente, como é o caso de vidas negras. Como são poucas as obras que da literatura canônica ou reconhecida pela crítica que dão voz a personagens negros, apenas por esse critério o texto já merece leitura.

Os 15 contos do livro estão divididos em duas partes: "Histórias de Meninos" e "Homem em Janeiro". A primeira dá ênfase à fase infantil e adolescente de seus personagens e a segunda à fase adulta a partir de temas variados e linguagem envolvente. Todas as narrativas, embora independentes entre si, têm um ponto em comum: dão histórias de personagens negros que vivem das periferias de grandes cidades. Nelas é importante observar as histórias de luta, resiliência e sobrevivência de homens negros que, em suas vidas conturbadas, aprendem a resistir diariamente apesar de tudo.

A leitura dessas narrativas, mesmo que não tenha a pretensão de um amplo trabalho de crítica e análise literária, já é um movimento importante para a sensibilização do leitor quanto a uma formação humanizada. A forma dos textos e os temas que cada um aborda permitem também para leitores menos experientes e letrados literariamente uma experiência de "viver" realidades difíceis e conturbadas em contextos variados. Essa experienciação, de certa forma, permite uma 
maior sensibilidade relacionada a questões sociais - algo que a experiência de pandemia incita a exercitar.

\section{CONSIDERAÇÕES FINAIS}

No campo educacional, a pandemia provocada pela disseminação do COVID-19 obrigou atores educacionais a adequarem-se ao novo contexto social, marcado pelo isolamento e por novos processos de ensinar e de aprender, exigindo que a educação humanizadora fosse fortalecida para superação dos desafios educacionais apresentados a todos. Nesse contexto, a suspensão das aulas presenciais, em 2020, fez com que os atores educacionais buscassem novos caminhos para a criação de situações de aprendizagem eficazes a partir da perspectiva do ensino remoto, e a leitura literária pode ser vista como elemento potencializador.

Entendemos que a literatura, dadas as circunstâncias desse ensino, pode ser ferramenta propícia para uma educação mais humanizadora. Sob essa perspectiva, defendemos inicialmente a necessidade de a literatura continuar sendo objeto de trabalho e de formação do sujeito no contexto educacional. Mesmo que a necessidade de adoção de novas metodologias de ensino para garantir a continuidade do processo educacional seja uma prioridade, a literatura precisa resistir e ser mais estimulada ainda como objeto de leitura na formação de alunos da educação básica e do ensino superior.

Também ratificamos o poder humanizador da literatura, já fundamentado por Antonio Candido (1995), considerando todas as particularidades estéticas e temáticas que um texto literário pode apresentar. Em contextos complexos como o da pandemia de Covid-19, torna-se ainda maior o papel humanizador que a leitura literária proporciona, pois muitos textos literários permitem uma humanização de forma sensível e apenas com o contato do leitor com o texto, independentemente do espaço e do tempo de leitura.

Além disso, é preciso destacar que "O isolamento social causado pela COVID-19 levou bilhões de humanos à condição de reflexão e ao pensamento da necessidade mais efetiva de se considerar um ser social e histórico, pensante e capaz de encontrar uma saída para a educação da pandemia" (PASINI; CARVALHO; ALMEIDA, 2020, p. 6), e assim, nesse contexto de encontrar uma saída, a literatura é uma excelente alternativa dadas as suas particularidades especialmente de reflexão e sensibilização. 


\section{REFERÊNCIAS}

AGUIAR, Vera Teixeira de; BORDINI, Maria da Glória. Literatura: a formação do leitor alternativas metodológicas. 2. ed. Porto Alegre: Mercado Aberto, 1993.

AGUIAR E SILVA, Vitor Manuel. Teoria da literatura. Coimbra: Martins Fontes, 1976.

CANDIDO, Antonio. 0 direito à literatura. In: Vários Escritos. São Paulo: Duas Cidades, 1995.

A literatura e a formação do homem. Ciência e cultura. São Paulo. USP, 1972.

FREIRE, Paulo. Pedagogia da Autonomia. Saberes necessários à prática educativa.São Paulo: Paz e Terra, 2001.

Pedagogia do Oprimido.40.ed. São Paulo: Paz e Terra, 2005.

HONWANA, Luís Bernardo. Nós Matámos o Cão Tinhoso. Disponível em:http://www.prof2000.pt/users/leiria/cao tinhoso.htm . Acesso em: 20 maio 2015.

KHALIL, Marisa Martins Gama. Memória e Espacialidades Reais e Ficcionais em "Nós Choramos pelo Cão Tinhoso", de Ondjaki. Revista Cerrados, Brasília, v. 21, n. 34, p. 191-206, 2012. Disponível em: https://periodicos.unb.br/index.php/cerrados/article/view/25778/22655 . Acesso em: 18 maio 2019.

MALARD, Letícia. Ensino e literatura no $2^{\circ}$ grau: problemas \& perspectivas. Porto Alegre:Mercado Aberto, 1985.

MEDEIROS, Mario. Gosto de amora. São Paulo: Malê, 2019.

MENESES, Adélia Bezerra de. O sentido formativo da literatura. [s. d.] Disponível em:<http://www.iea.usp.br/publicacoes/textos/sentidoformativoliteratura.pdf> Acesso em: 21 fev. 2016.

ONDJAKI. Nós chorámos pelo Cão Tinhoso. In: Os da minha rua. Lisboa, Caminho, 2007.

OURIQUE, João Luis Pereira. Literatura e formação do leitor: escola e sociedade, ensino e educação. ljuí: Ed. Unijuí, 2015.

PASINI, Carlos Giovani; CARVALHO, Élvio de; ALMEIDA, Lucy Hellen. A educação híbrida em tempos de pandemia: algumas considerações. 2020. Disponível em: https://www.ufsm.br/app/uploads/sites/820/2020/06/Textos-para-Discussao-09-EducacaoHibrida-em-Tempos-de-Pandemia.pdf. Acesso em: abr. 2020.

PEREIRA, Cilene Margarete; CAVALCANTI, Luciano Dias. Reflexões sobre literatura, direitos humanos e ensino a partir do texto literário. Interfaces, Guarapuava-PR, v. 10 n. 4, p. 65- 74, 2019. Disponível em: 
https://revistas.unicentro.br/index.php/revista_interfaces/article/view/6020/4373. Acesso em: 20 jan. 2020.

PORTO, Ana Paula Teixeira; PORTO, Luana. Ensino de literatura e formação do leitor na era digital: algumas proposições. In: OURIQUE: João Luis Pereira (Org.). Literatura e formação do leitor: Escola e sociedade, ensino e educação. ljuí: Unijuí, 2015, p. 89-109.

TODOROV, Tzvetan. A literatura em perigo. Trad. Caio Meira. Rio de Janeiro: DIFEL, 2009.

ZILBERMAN, Regina. Leitura literária e outras leituras. In: BATISTA, Antônio Augusto (Org.). Leitura-práticas, impressos, letramentos. Belo Horizonte: Autêntica, 1999. 